\title{
Functionally Graded Material of 304L Stainless Steel and Inconel 625 Fabricated by Directed Energy Deposition: Characterization and thermodynamic modeling
}

\author{
Beth E. Carroll ${ }^{\mathrm{a}}$, Richard A. Otis ${ }^{\mathrm{a}}$, John Paul Borgonia ${ }^{\mathrm{b}}$, Jong-ook Suh ${ }^{\mathrm{b}}$, R. Peter Dillon ${ }^{\mathrm{b}}$, \\ Andrew A. Shapiro ${ }^{\mathrm{b}}$, Douglas C. Hofmann ${ }^{\mathrm{b}}$, Zi-Kui Liu ${ }^{\mathrm{a}}$, Allison M. Beese ${ }^{\mathrm{a}^{*}}$ \\ ${ }^{a}$ Department of Materials Science \& Engineering, Pennsylvania State University, University \\ Park, PA, 16802, USA \\ ${ }^{\mathrm{b}}$ Jet Propulsion Laboratory, California Institute of Technology, Pasadena, CA, 91109, USA \\ *Corresponding author: \\ amb961@psu.edu, 814-865-1523, 202A Steidle Bldg., University Park PA, 16802
}

\begin{abstract}
Many engineering applications, particularly in extreme environments, require components with properties that vary with location in the part. Functionally graded materials (FGMs), which possess gradients in properties such as hardness or density, are a potential solution to address these requirements. The laser-based additive manufacturing process of directed energy deposition (DED) can be used to fabricate metallic parts with a gradient in composition by adjusting the volume fraction of metallic powders delivered to the melt pool as a function of position. As this is a fusion process, secondary phases may develop in the gradient zone during solidification that can result in undesirable properties in the part. This work describes experimental and thermodynamic studies of a component built from 304L stainless steel
\end{abstract}


incrementally graded to Inconel 625 . The microstructure, chemistry, phase composition, and microhardness as a function of position were characterized by microscopy, energy dispersive spectroscopy, X-ray diffraction, and microindentation. Particles of secondary phases were found in small amounts within cracks in the gradient zone. These were ascertained to consist of transition metal carbides by experimental results and thermodynamic calculations. The study provides a combined experimental and thermodynamic computational modeling approach toward the fabrication and evaluation of a functionally graded material made by DED additive manufacturing.

Keywords: Additive manufacturing, functionally graded material, thermodynamic modeling, laser deposition, microstructure 


\section{Introduction}

Functionally graded materials (FGM) are highly desirable in applications in which the service conditions of a part vary with location and therefore the material requirements also vary with location [1]. Extreme-environment applications such as in aerospace [2] or nuclear power generation require parts that, for instance, must perform at radically different temperatures at different locations in the part [3]. Therefore, such properties as corrosion and oxidation resistance, strength, toughness, wear resistance, light weight, and reasonable cost may all be required in, for instance, various regions of an engine component, but are rarely if ever all found in a single material [4], [5]. Joining of dissimilar materials or functional grading of two or more materials is therefore required [1], [6]. Functionally graded materials are divided into two types: those made by construction, such as adding layers to build up a part, and those made solely by mass transport, or use of diffusion to create a gradient [2].

Conventional fusion welding is routinely used to join similar metals, and sometimes to join dissimilar metals. However, it is common when welding dissimilar metals to use intermediate layers that separate the two dissimilar metals[7], or to use high-energy-density techniques such as laser welding to prevent such problems as cracking or embrittlement [8]. These issues are usually caused by lack of solubility, atomic structure mismatch, variation in thermal expansion, and the formation of thermodynamically stable brittle intermetallic phases along the gradient composition [8]. Irregular compositional inhomogeneities in the weld also present difficulties such as susceptibility to corrosion and hydrogen cracking [9].

Avoiding melting altogether through the use of solid state joining processes (e.g. ultrasonic welding (UW) and friction stir welding (FSW)) is one way to prevent cracking or 
embrittlement in the joining of two dissimilar metals. In FSW, the two workpieces are severely deformed by a much harder tool and the weld is formed in the solid state [10]. This develops a purely mechanical bond, avoiding the above-mentioned issues that can occur in fusion welding, but creates a very narrow boundary zone between the two metals rather than a gradient of composition [11]. However, differences in material properties between the two component materials can result in thermal and mechanical residual stresses in a structural component. Use of a graded structure without a narrow boundary zone can reduce the occurrence of these stresses [2], [12].

The FSW technique can also be applied to create bulk materials with a gradient of properties through control of grain size with the possibility of creating gradient microstructures. Instead of welding, friction stir processing (FSP) and submerged friction stir processing (SFSP) can be used to change the properties of a metal in bulk by applying severe plastic deformation over a larger area [13].

Additive manufacturing (AM) is ideally suited to the constructive method of preparing functionally graded materials. In particular, the directed energy deposition (DED) method, in which powder is fed into the melt pool under a moving laser [14], can be employed for FGM by varying the powder composition between layers, which is readily done using a deposition machine equipped with two or more powder feeders [15], [16]. This process has been used to prepare graded structures of titanium alloys [15]-[18]. However, as DED is a fusion-based process, the potential problems of dissimilar metal welding, namely, the formation of undesirable intermetallic phases, must be addressed [11], [19].

The nickel-based superalloy Inconel 625 (IN625) and grade 304L stainless steel (SS304L) were selected for this study. These alloys both exhibit a single face-centered cubic 
crystal structure from the melt down to room temperature, with no allotropic phase transformations, and the principal constituents of the alloys, namely $\mathrm{Fe}, \mathrm{Cr}$, and $\mathrm{Ni}$, have good solubility. As a graded alloy system, it would be useful in applications that require both strength and corrosion resistance at elevated temperature, where IN625 is suitable, and lower cost and mass, where SS304L is suitable. One such application is in high-end automobile engine valve stems [11] while another application is in functionally graded, corrosion resistant coatings. The fabrication of both SS304L and IN625 parts by additive manufacturing has been studied [20][23]. Furthermore, gradients of nickel-based alloys to stainless steels have been previously studied [24]-[26]. These have consisted of 316 stainless steel graded to a precipitationhardenable nickel-based alloy such as Inconel 718 [24] or Rene88DT [25], [26]. However, when these alloys are fabricated using additive manufacturing, the microstructure is effectively in the solution-treated condition [27], and subsequent heat treatments are required to develop the mechanical properties of wrought material [28]. Therefore, the non-precipitation-hardenable alloy IN625 was selected for this study.

Selective laser melting (SLM), a variant of additive manufacturing in which powder is spread in layers and locally melted with a laser heat source, has been used to fabricate SS304L [20], [21]. The microstructure of these parts is principally austenitic and features appear that correspond to individual laser passes. Directed energy deposition has also been used to create parts of austenitic stainless steel [29]-[31]. These studies, which have focused mainly on process optimization, have succeeded in producing parts with higher yield and ultimate strengths than wrought material, although with reduced ductility.

In IN625 deposited by directed energy deposition, the microstructure shows dendrites oriented parallel to the build direction and which appear as cellular when viewed perpendicular 
to the build direction [22]. These observations are similar to those reported by Dinda and coworkers [23], who observed that dendritic structures follow the direction of heat flow.

In this work, a part fabricated by DED with a structure graded from type SS304L to the nickel-based alloy IN625 was evaluated for elemental composition, microstructure, phase composition, and mechanical properties. The structure and properties of the gradient zone were compared to the constituent alloys deposited by DED at each end of the process. The phases found in the gradient zone were compared to those obtained by CALculation of PHAse Diagrams (CALPHAD) modeling to ascertain the viability of using CALPHAD to predict the appearance of the experimentally observed structures in this system.

\section{Experimental}

A square post, $16 \mathrm{~mm}$ wide and $34 \mathrm{~mm}$ tall, was built on a substrate of SS304L as shown in Figure 1. IN625 and SS304L powders of compositions noted in Table 1 were used (Carpenter Technology Corporation). The gradient part was built using a directed energy deposition system (RPM 557 Laser Deposition System) under an argon atmosphere. This system allows up to four powders to be added to the build during fabrication and the volumetric fraction of each powder can be changed by about $1 \%$ per deposited layer. Twenty layers of SS304L were deposited before grading began. In the graded region, the volume of SS304L powder was reduced by $4 \%$ and IN625 powder increased by the same amount in each successive layer, for a total of 24 layers. Nineteen layers of IN625 were deposited on top of the gradient zone. Layers were approximately $0.5 \mathrm{~mm}$ tall and were built by a $910 \mathrm{~W}$ YAG laser with a hatch angle of 60 degrees. 
The post was sectioned using wire electric discharge machining as shown in Figure 1. The cut section was mounted in epoxy and prepared using standard metallographic techniques. The sample was etched electrolytically in $10 \%$ oxalic acid for 10 seconds at $4 \mathrm{~V}$. The microstructure was evaluated using visible-light microscopy (Keyence VHX).

X-ray diffraction patterns were collected using a Bragg-Brentano-type diffractometer (Panalytical Empyrean) with a $\theta-\theta$ goniometer. The $\mathrm{X}$-ray source was a $\mathrm{CuK} \alpha$ tube operated at $45 \mathrm{kV}$ and $40 \mathrm{~mA}$ and having a wavelength of $1.54 \AA$. Variable incident and diffracted-beam slits were used to obtain a line focus of $10 \mathrm{~mm}$ by $1 \mathrm{~mm}$, allowing a narrow range of composition in the gradient zone to be analyzed. An area detector (Pixcel 2.0) in 1D scan mode was used to collect the diffracted beam. As variable-slit diffraction patterns inherently possess a sloped background, the patterns were converted to fixed-slit equivalents in postprocessing (Jade 2010). Energy dispersive spectroscopy (EDS) was performed in a scanning electron microscope (FEI Quanta 200) with a silicon drift detector (Oxford X-act PentaFET Precision). The spectra were collected and analyzed in a semi-quantitative manner (Oxford AZtec version 2.4). It should be noted that all analyzed compositions are in weight percent. The planned composition, which was varied volumetrically, was converted to planned weight percent using the densities of IN625 and SS304L.

Microhardness was measured using Vickers indenter (Leco V-100-C1) with a load of 300 $\mathrm{g}$ and a dwell time of 15 seconds. A minimum of five indents were taken for each layer of the sample analyzed.

\section{Computation}


Because the mechanical properties of alloys are strongly coupled to the relative stability of constituent phases, which gives rise to particular morphologies at the micro-scale, thermodynamic analyses of these systems yield insight into the propensity of gradient alloys to precipitate undesirable phases during processing. The equilibrium phase diagram serves as a first-order indication for this tendency and can be computed using the well-established CALculation of PHAse Diagrams (CALPHAD) method [32], [33]. In this approach the Gibbs energies of all stable and metastable phases are constructed as parameterized functions evaluated from experimental data and theoretical data obtained first-principles calculations based on density functional theory [34]. Parameters for many alloy systems, including those for IN625 and SS304L, are tabulated in commercial databases and the open literature.

A computational study of phase relations across the entire gradient can provide the fullest picture of how the evolution of phases across the gradient impacts the microstructure and, ultimately, the mechanical properties. However, a general alloy thermodynamic database covering the entire composition range from IN625 to SS304L is not available because multicomponent thermodynamic databases are usually optimized for a particular alloy system. In the present work as the first order of approximation, the Thermo-Calc TCFE7 database [35] is used for calculations of phase stability across the gradient region because it also describes the phase relations in IN625 well. In the early publications on Ti-6Al-4V to V and $304 \mathrm{~L}$ to Invar 36 gradient alloys [11], [19], the temperatures of calculations were selected in terms of experimental microstructure features. In the present work, several temperatures are tested based on the equilibrium phase fractions computed as a function of temperature at a composition in the gradient zone with distinct features as discussed below. 


\section{Results \& Discussion}

Microstructural examination of the built specimen using visible light indicates that a diffuse gradient zone without sharp distinctions was successfully produced. The microstructure obtained at a range of compositions as noted throughout the gradient zone is given in Figure 2. The gradient microstructure resembles that of AM SS304L in the composition range from 85$100 \mathrm{wt} \% \mathrm{SS} 304 \mathrm{~L}$ (Figure 2Figure 2a-c). In this structure, the light areas are austenite and ferrite, and the dark regions correspond to grain boundaries [36]. The composition range from about 20-50 wt\% IN625 (Figure 2c-e) contains a microstructure unique to the gradient zone. These layers resemble cellular dendrites with a high level of contrast. In the range of about 50\%-100 wt\% IN625 (Figure 2f-g) the gradient appears much like that of deposited IN625 (Figure 2h), with columnar dendrites. During fabrication, the component was rotated 60 degrees between layers, i.e., a 60 degree hatch angle was used. Since columnar dendrite growth follows the direction of the laser [23], the dendrite structure, while continuous between layers, is disorganized and does not show extensive dendrite growth between layers. Overall, the microstructure demonstrates contiguous features across the width of the gradient zone.

The composition across the gradient zone follows the planned composition with no major deviations. Semi-quantitative EDS results (symbols) are compared to the designed composition of the gradient (lines) in Figure 2, and demonstrate the successful fabrication of the part to the intended composition. No significant excursions were seen, indicating a minimum of evaporative losses during the build and reasonable adherence to planned layer thickness. One of the four series of spectra taken along the IN625-rich end of the gradient demonstrated a departure from the expected values. This may be due to the slight irregularity of the layer thickness in this area of the specimen. 
Cracks of several hundred microns in length were found in a region composed of approximately $79 \mathrm{wt} \% \mathrm{SS} 304 \mathrm{~L}$ and $21 \mathrm{wt} \% \mathrm{IN} 625$. There is no macroscopic compositional segregation to indicate the reason for such cracks. While austenitic stainless steels that solidify directly into the austenite phase are known to be susceptible to solidification cracking during welding, stainless steel 304L solidifies from primary dendritic ferrite to austenite, and is therefore not susceptible solidification cracking [9], [37], [38]. This indicates that the cracks found are not due to intrinsic solidification cracking in the stainless steel.

The $79 \mathrm{wt} \%$ SS304L region was further investigated by SEM and EDS to determine if compositional or microstructural variations were responsible for the development of cracks. A high-magnification BSE image of a crack found at a design composition of about $79 \mathrm{wt} \%$ SS304L and $21 \mathrm{wt} \%$ IN625 is shown in Figure 4a. The planned composition and that measured by EDS (in weight percent, average of two spectra) are tabulated in Figure 4b, and show that the design composition near the crack is approximately the same as that obtained experimentally. The variation of a few percent is readily explained by the limitations of the EDS technique, which has an intrinsic uncertainty of about $1 \mathrm{wt} \%$ [39].

EDS mapping of the cracked area denoted by the box in Figure 4a demonstrates the presence of a second phase, enriched in $\mathrm{Nb}$ and Mo, within the cracked region (Figure 4c-h). While carbon cannot be reliably quantified with EDS, the $\mathrm{C}, \mathrm{Nb}$, and Mo maps suggest that the secondary phases consist of $\mathrm{Nb}$ - and Mo-containing carbides (Figure 4h). While the weight ratio of $\mathrm{Nb}$ to Mo in the matrix was found to be approximately 0.5 , EDS point analysis in the cracked region showed that this ratio increased to approximately 2 in the cracked region. Thermodynamic calculations performed at the composition where cracks were present agreed that the weight ratio of $\mathrm{Nb}$ to Mo should be 0.5 in the fcc matrix, and showed that in the metal 
monocarbides found at equilibrium, the ratio of $\mathrm{Nb}$ to Mo increases three orders of magnitude while other potential carbides $\mathrm{M}_{7} \mathrm{C}_{3}$ and $\mathrm{M}_{23} \mathrm{C}_{6}$ have decreasing $\mathrm{Nb}$ to Mo ratios. The discrepancy in order of magnitude in these ratios between experimental data and the thermodynamic calculation can be explained at least partially by the fact that EDS point analysis probes a volume that contains not just the surface point in question, but an interaction volume below that point, meaning that some amount of matrix material was likely incorporated in the point analysis, reducing the relative ratio of $\mathrm{Nb}$ to $\mathrm{Mo}$. Nevertheless, the increase in the $\mathrm{Nb}$ to Mo ratio in the EDS analysis is indicative of the formation of metal monocarbides containing $\mathrm{Nb}$ and Mo.

The crystalline structure of the built gradient alloy was investigated to ascertain what phases were present and compare these to the structure of the constituent alloys at either end of the build. The X-ray diffraction patterns collected across the gradient are compared with patterns from the deposited IN625 and SS304L at each end of the gradient zone (Figure 5). The as-deposited SS304L, which when conventionally processed contains both the face-centered cubic (fcc) austenite phase and the body-centered cubic (bcc) ferrite phase, shows a very small amount of ferrite in agreement with prior observations [25], [40]. The as-deposited IN625 also shows an austenitic structure similar to that seen in reference [23]. The principal phases in IN625 and SS304L are both fcc and show lattice parameters in this study of $3.60 \AA$ and $3.59 \AA$ respectively. There is no significant change in peak position across the gradient zone, indicating that the gradient zone is structurally homogeneous. No ferrite or any other phase was observed in the XRD patterns of the gradient zone, which demonstrates that macroscopic quantities of secondary phases did not appear. Therefore, the secondary phase observed by SEM occurs at a concentration of less than a few percent [41]. 
The variation in XRD relative peak height along the length of the gradient is indicative of texture. Prior work on additive-manufactured IN625 has demonstrated large variation in peak height between horizontal and vertical sections of deposited material, which were correlated to the highly textured columnar microstructure observed [42]. Furthermore, Dinda et al. [23] observed that columnar dendritic growth in AM IN625 tended to follow the movement of the laser, with crystallographic orientation shifting by 90 degrees between layers when the laser direction was reversed (a hatch angle of 180 degrees). The component currently under study was fabricated using a 60 degree hatch angle, meaning that six layers are built before the laser scanning direction, and hence the crystallographic orientation, reaches the 'start' position again. The $1 \mathrm{~mm}$ wide line focus of the XRD, and the slight irregularity of the build layers, makes it impossible to isolate a single layer for XRD study. Therefore, a minimum of two to three layers are analyzed in each XRD pattern, convolving the texture contribution of the analyzed layers.

Thermodynamic calculation of the phase relations in the crack region of the gradient, shown in Figure 4 and discussed above, requires determination of the as-deposited composition and one or more representative temperatures. For the composition, the EDS measurements in Figure 4 provide the atomic ratios of the most abundant components, but quantitative information about the components present in small amounts, in particular the $\mathrm{C}$ content, cannot be directly obtained by this experimental technique. This issue can be resolved by taking advantage of knowing the constitutive powder compositions (Table 1) as well as the fact that the as-deposited compositions approximately obey the rule of mixtures (Figure 3). First, the weight fraction of $\mathrm{Cr}, \mathrm{Fe}, \mathrm{Mo}, \mathrm{Nb}, \mathrm{Mn}$, and $\mathrm{Ni}$ from SS304L to IN625 is linearly interpolated with respect to the weight fraction of SS304L powder. Components of either powder where only an upper bound on the composition is known are taken to be zero at that end of the gradient. Next, 
the measured atomic ratios from the crack region are normalized, giving (weight percent) 57\% Fe, $19 \% \mathrm{Ni}, 1.6 \% \mathrm{Mo}, 0.61 \% \mathrm{Nb}, 1.2 \% \mathrm{Mn}$, and $21 \% \mathrm{Cr}$. By inverting the interpolation function for each component, the fraction of SS304L powder required to yield that composition can be computed and averaged over all components, resulting in an estimated SS304L weight fraction of $82 \%$ in the crack region. Note that $\mathrm{Cr}$ and $\mathrm{Mn}$ are excluded from the average because the difference in composition across the gradient is too small to meaningfully invert the interpolation function. Finally, this value is inserted back into the linear interpolation between the powder compositions, this time including the trace elements $\mathrm{Al}, \mathrm{C}, \mathrm{Co}, \mathrm{Si}$ and $\mathrm{Ti}$. Based on this evaluation, the local composition in the crack region of the gradient is estimated to be $57 \%$ Fe, $20 \%$ Cr, $19 \%$ Ni, 1.5\% Mo, 1.1\% Mn, 0.61\% Si, 0.60\% Nb, 0.053\% Co, $0.016 \%$ Al, 0.014\% $\mathrm{C}$, and $0.012 \% \mathrm{Ti}$.

Thermodynamic calculations at the composition near the crack formation region are shown in Figure 6, depicting the computed equilibrium phase fractions as a function of temperature. The phase fractions are plotted on a logarithmic scale to make minor phase amounts more apparent. The calculations shown in Figure 6 are equivalent to a hypothetical infinitely slow cooling or heating process in which the alloy is allowed to equilibrate at each temperature step. The fcc matrix phase begins to precipitate from the melt near $1400^{\circ} \mathrm{C}$. A stability region between $580^{\circ} \mathrm{C}$ and $1100^{\circ} \mathrm{C}$ for $(\mathrm{Nb}, \mathrm{Mo}) \mathrm{C}$ monocarbide (MC) precipitates is observed in the calculation. Several intermetallics are also predicted to be present at equilibrium at relatively low temperatures, though they are not experimentally observed in this work.

Starting from highest temperature, a hexagonal Laves $(\mathrm{C} 14)$ phase begins precipitation at $950^{\circ} \mathrm{C}$ before peaking in amount at $800^{\circ} \mathrm{C}$ and disappearing to form $\mathrm{NbNi}_{3}$, which is stable until $520^{\circ} \mathrm{C}$. The $\sigma$ phase begins forming at $850^{\circ} \mathrm{C}$ and increases in amount until reaching $500^{\circ} \mathrm{C}$, the 
temperature lower limit of the calculation. G phase, an intermetallic silicide [43], begins to precipitate at $700^{\circ} \mathrm{C}$. Another carbide, $\mathrm{M}_{23} \mathrm{C}_{6}$, is also predicted stable starting from $600^{\circ} \mathrm{C}$. The intermetallics may not be present in the current system, despite thermodynamic stability over a wide temperature range, due to the fast cooling rates (Figure 4c) and sluggish precipitation kinetics [44] compared to the discussed carbides [45]. Substantial solubility of Mo in NbC has been reported over a wide temperature range [46], though the TCFE7 thermodynamic database does not reflect this. The stability of $\mathrm{NbC}$ during high-temperature heat treatment of $\mathrm{Nb}$ microalloyed austenitic steels has been reported previously with similar thermodynamic results [47]. $\mathrm{M}_{23} \mathrm{C}_{6}$ carbides with facile precipitation kinetics in interdendritic regions have been reported in Mo-containing austenitic stainless steels [45], [48], though in this case the stable temperature range may be too low for that carbide to be observed.

For design purposes, it is desirable to examine not only the temperature-dependent phase relations at fixed composition, but also the phase relations across the entire gradient. Because these thermodynamic calculations are carried out at equilibrium while the actual fabrication process is highly non-isothermal, some care must be taken to choose representative temperatures for the phase relations. When only a few phases are known to play a role across the gradient, one solution is to consider the isothermal transformation kinetics and select a temperature close to where a key phase transformation starts to be kinetically frozen out. This was the approach used previously in the selection of $750^{\circ} \mathrm{C}$ as the temperature of interest in the Ti-6Al-4V to $\mathrm{V}$ gradient[19], since the + transformation is known to stop near that temperature at typical cooling rates of additive manufacturing. With this method the composition dependence of the kinetics is not considered; for example, in cases where the diffusion coefficient of a component varies significantly with composition, deviations from experimental observations are to be 
expected. Another limitation is that equilibrium computations, by definition, exclude precipitates that are metastable at some or all temperatures, e.g., martensite in ferrous alloys. To the greatest feasible extent, the system-specific transformation kinetics present in a given or hypothetical gradient alloy should be considered prior to the interpretation of equilibrium thermodynamic calculations. For the present work, a temperature range of $950-1100^{\circ} \mathrm{C}$ is considered based on the results in Figure 6, where $1100^{\circ} \mathrm{C}$ is the approximate maximum temperature in the crack region for the precipitation of the $\mathrm{MC}$ phase.

In Figure 7 the calculated equilibrium phase fractions as a function of the weight fraction of IN625 powder are shown for the selected temperature range of $950-1100^{\circ} \mathrm{C}$. A weight fraction of zero IN625 powder corresponds to the SS304L end of the gradient, making comparisons to Figure 3 reasonable since the distance from the SS304L baseplate of the sample is nearly linear with the weight fraction of IN625. Across this temperature range the fcc matrix phase is dominant, with other phases appearing in only minor amounts. At $1100^{\circ} \mathrm{C}$ the $\mathrm{MC}$ phase fraction has a maximum at $23 \mathrm{wt} \% \mathrm{IN} 625(77 \mathrm{wt} \% \mathrm{SS} 304 \mathrm{~L})$, which is close to the estimated composition of the crack region, 18wt $\%$ IN625 (82wt\% SS304L). The MC stability window ranges from 1-72 wt \% IN625 (99-28 wt $\% \mathrm{SS} 304 \mathrm{~L})$ at $950^{\circ} \mathrm{C}$ to $7-58 \mathrm{wt} \% \mathrm{IN6} 25(93-42$ $\mathrm{wt} \% \mathrm{SS} 304 \mathrm{~L})$ at $1100^{\circ} \mathrm{C}$. The $\mathrm{NbNi}_{3}$ phase has a stability region that starts at $30 \mathrm{wt} \% \mathrm{IN} 625(70$ $\mathrm{wt} \% \mathrm{SS} 304 \mathrm{~L})$ at $950^{\circ} \mathrm{C}, 48 \mathrm{wt} \% \mathrm{IN} 625(52 \mathrm{wt} \% \mathrm{SS} 304 \mathrm{~L})$ at $1050^{\circ} \mathrm{C}$, and extends almost all the way to IN625. The $\mathrm{C} 14$ and $\sigma$ phases only appear at $950^{\circ} \mathrm{C}$ and have small stability regions peaking at $22 \mathrm{wt} \%$ IN625 (78 wt $\%$ SS304L) and $58 \mathrm{wt} \%$ IN625 (42 wt\% SS304L), respectively. The MC phase has a stability window requiring sufficiently high concentrations of $\mathrm{Nb}$ and Mo (provided by IN625) as well as C (provided by SS304L). Avoiding the precipitation of this phase for crack mitigation purposes is not possible using only linear combinations of SS304L 
and IN625 powder because the critical concentrations will always be exceeded; the composition and temperature stability windows are simply too large. A potential approach would use elemental powders to vary the $\mathrm{Nb}$ and Mo content nonlinearly versus mixing alloy powder by using more powder feeders.

The microhardness results are shown in Figure 8, overlaid on the compositional results for $\mathrm{Fe}$ and Ni. There are no significant excursions in hardness above or below the range established by the hardness of the deposited SS304L and IN625 at the ends of the sample. The hardness of the deposited base alloys are approximately 50HV higher than manufacturer values for wrought material [49], [50], in accordance with observations made on additive-manufactured 316L stainless steel by Lin et al. [25], [26]. The base alloy hardness also descends slightly with increasing height from the baseplate, similar to behavior seen in directed energy deposition of titanium alloys [51]-[53]. The microhardness trend in the gradient zone, however, does not precisely overlie the compositional gradient. Rather, the hardness drops slightly as IN625 is introduced, and at a composition of about $71 \mathrm{wt} \% \mathrm{SS} 304 \mathrm{~L}$ then begins to climb, reaching the level of deposited IN625 at about a composition of $47 \mathrm{wt} \% \mathrm{SS} 304 \mathrm{~L}$. This trend in hardness is in approximately the same composition range to that of the cellular dendritic microstructure shown in Figure 2c-e, and similar results were reported in laser welding of bulk IN625 and SS304L [3].

Figure 9 shows a hardness indent taken at a design composition of $83 \mathrm{wt} \% \mathrm{SS} 304 \mathrm{~L}$, which shows two cracks radiating away from the indentation that were not present before the material was indented. It should be noted that in the over 190 hardness measurements performed, this was the only hardness indent that showed cracking. Therefore, the cracks were only seen in the area where carbides were found with EDS analysis and confirmed with thermodynamic calculations. 


\section{Conclusions}

A graded component without sharp compositional, structural, or microstructural boundaries was successfully fabricated from SS304L to IN625 using directed energy deposition. Micron-sized particles of a secondary phase responsible for development of cracks in fabrication and microhardness were observed near the SS304L end of the gradient zone (approximately 82 $\mathrm{wt} \% \mathrm{SS} 304 \mathrm{~L})$. Thermodynamic calculations performed using the CALPHAD method predict the stability of a refractory metal monocarbide in this region while EDS mapping shows the cracks are rich in $\mathrm{Mo}$ and $\mathrm{Nb}$. These results suggest the secondary phase is a metal monocarbide of the form $(\mathrm{Mo}, \mathrm{Nb}) \mathrm{C}$. Texturing produces peak height variation in XRD and changes in microhardness along the length of the gradient zone, but no change in overall structure. This study demonstrates the feasibility of building graded components using directed energy deposition, shows the viability of CALPHAD-based phase stability calculations as a tool for gradient alloy process design, and highlights the need to design for possible secondary phases that may appear and the potential variation in properties as a result of build conditions. 


\section{Acknowledgements}

The authors gratefully acknowledge the financial support of the National Science Foundation through award number CMMI-1402978. Any opinions, findings, and conclusions or recommendations expressed in this material are those of the authors and do not necessarily reflect the views of the National Science Foundation. R.A.O. received funding from a NASA Space Technology Research Fellowship under grant NNX14AL43H. We also acknowledge technical assistance from Ashley Reichardt with preliminary thermodynamic calculations. Part of this research was carried out at the Jet Propulsion Laboratory, California Institute of Technology, under a contract with the National Aeronautics and Space Administration (NASA). 


\section{Table and Figure Captions}

Table 1. Composition of powders used in weight percent.

Figure 1. (a) Schematic of gradient alloy specimen. Dotted line shows where part was sectioned for analysis. (b) Photograph of specimen after sectioning.

Figure 2. Microstructure of gradient zone from 100\% SS304L (a) to 100\% IN625 (h), with weight fractions of SS304L and IN625 indicated. The gradient microstructure resembles that of austenitic SS304L up to a composition of about $15 \mathrm{wt} \%$ IN625 (a,b,c). A high-contrast cellular dendritic structure appears between $15 \mathrm{wt} \%$ and about $50 \mathrm{wt} \%$ IN625 (c,d,e), and from $50 \mathrm{wt} \%$ to $100 \mathrm{wt} \%$ IN625 $(\mathrm{f}, \mathrm{g}, \mathrm{h})$ the microstructure appears much as IN625, with columnar dendrites.

Figure 3. Measured (symbols) and planned (lines) composition of gradient alloy post. The distance from the SS304L baseplate, shown on the x-axis, is nearly linear with the weight fraction of IN625 powder, such that distances less than 2mm correspond to SS304L, while $15 \mathrm{~mm}$ and above correspond approximately to IN625.

Figure 4. BSE image of crack (a); table of planned and measured composition in weight percent 100 microns from crack (b); EDS maps of constituent elements (c-h).

Figure 5. X-ray diffraction patterns along the length of the gradient zone, with weight fractions of two alloys indicated. 
Figure 6. Equilibrium phase fractions as a function of temperature for the measured composition of the SS304L-rich gradient zone boundary are computed using the Thermo-Calc TCFE7 database. This is equivalent to a hypothetical infinitely slow cooling or heating process in which the alloy is allowed to equilibrate at each temperature step. The phase fractions are plotted on a logarithmic scale to make minor phase amounts more apparent. The metal monocarbide (MC) phase is stable from approximately $580^{\circ} \mathrm{C}$ to $1100^{\circ} \mathrm{C}$.

Figure 7. Calculated equilibrium phase fractions as a function of the weight fraction of IN625 powder. A weight fraction of zero corresponds to the SS304L end of the gradient. The phase fractions are computed using the Thermo-Calc TCFE7 database and plotted on a logarithmic scale to make minor phase amounts more apparent. At $1100^{\circ} \mathrm{C}$ the metal monocarbide (MC) phase fraction has a maximum at $23 \mathrm{wt} \%$ IN625. The fcc matrix phase is dominant at all temperatures shown.

Figure 8. Microhardness of the gradient alloy overlaid on Fe and Ni composition. Microhardness values are an average of five measurements, with standard deviation indicated by error bars. 
Figure 9. Microhardness indent showing radiating cracks (arrows) arrested after 100 microns or less. 


\section{References}

[1] A. Mortensen and S. Suresh, "Functionally graded metals and metal-ceramic composites: Part 1 Processing," Int. Mater. Rev., 1995.

[2] S. Suresh and A. Mortensen, Fundamentals of Functionally Graded Materials. London: IOM Communications Ltd, 1998.

[3] M. Shakil, M. Ahmad, N. H. Tariq, B. a. Hasan, J. I. Akhter, E. Ahmed, M. Mehmood, M. a. Choudhry, and M. Iqbal, "Microstructure and hardness studies of electron beam welded Inconel 625 and stainless steel 304L," Vacuum, vol. 110, pp. 121-126, 2014.

[4] V. Birman and L. W. Byrd, "Modeling and Analysis of Functionally Graded Materials and Structures," Appl. Mech. Rev., vol. 60, no. 5, p. 195, 2007.

[5] Z. Sun and J. C. Ion, "Review Laser welding of dissimilar metal combinations," J. Mater. Sci., vol. 30, pp. 4025-4214, 1995.

[6] F. Findik, "Recent developments in explosive welding," Mater. Des., vol. 32, no. 3, pp. 1081-1093, 2011.

[7] R. W. Messler, Principles of Welding: Processes, Physics, Chemistry, and Metallurgy. New York: John Wiley \& Sons, Inc., 1999.

[8] Z. Sun and R. Karppi, "The application of electron beam welding for the joining of dissimilar metals: An overview," J. Mater. Process. Technol., vol. 59, no. 3 SPEC. ISS., pp. 257-267, 1996.

[9] S. Kou, Welding Metallurgy, 2nd ed. Hoboken, NJ: John Wiley \& Sons, Inc., 2003.

[10] J. A. Schneider, “Temperature Distribution and Resulting Metal Flow," in Friction Stir Welding and Processing, R. S. Mishra and M. W. Mahoney, Eds. Materials Park, OH: ASM International, 2007.

[11] D. C. Hofmann, J. Kolodziejska, S. Roberts, R. Otis, R. P. Dillon, J.-O. Suh, Z.-K. Liu, and J.-P. Borgonia, "Compositionally graded metals: A new frontier of additive manufacturing,” J. Mater. Res., vol. 29, no. 17, pp. 1899-1910, 2014.

[12] J. J. Sobczak and L. Drenchev, "Metallic Functionally Graded Materials : A Specific Class of Advanced Composites," vol. 29, no. 4, pp. 297-316, 2013.

[13] D. C. Hofmann and K. S. Vecchio, "Submerged friction stir processing (SFSP): An improved method for creating ultra-fine-grained bulk materials," Mater. Sci. Eng. A, vol. 402, no. 1-2, pp. 234-241, Aug. 2005.

[14] W. E. Frazier, "Metal additive manufacturing: A review," J. Mater. Eng. Perform., vol. 23, no. 6, pp. 1917-1928, 2014.

[15] R. Banerjee, P. C. Collins, D. Bhattacharyya, S. Banerjee, and H. L. Fraser, "Microstructural evolution in laser deposited compositionally graded alpha/beta titaniumvanadium alloys," Acta Mater., vol. 51, no. 11, pp. 3277-3292, 2003. 
[16] P. C. Collins, R. Banerjee, S. Banerjee, and H. L. Fraser, "Laser deposition of compositionally graded titanium-vanadium and titanium-molybdenum alloys," Mater. Sci. Eng. A, vol. 352, no. 1-2, pp. 118-128, Jul. 2003.

[17] T. Qian, D. Liu, X. Tian, C. Liu, and H. Wang, "Microstructure of TA2/TA15 graded structural material by laser additive manufacturing process," Trans. Nonferrous Met. Soc. China, vol. 24, no. 9, pp. 2729-2736, 2014.

[18] H. S. Ren, D. Liu, H. B. Tang, X. J. Tian, Y. Y. Zhu, and H. M. Wang, "Microstructure and mechanical properties of a graded structural material," Mater. Sci. Eng. A, vol. 611, pp. 362-369, 2014.

[19] D. C. Hofmann, S. Roberts, R. Otis, J. Kolodziejska, R. P. Dillon, J.-O. Suh, A. a Shapiro, Z.-K. Liu, and J.-P. Borgonia, "Developing Gradient Metal Alloys through Radial Deposition Additive Manufacturing.," Sci. Rep., vol. 4, p. 5357, 2014.

[20] K. Guan, Z. Wang, M. Gao, X. Li, and X. Zeng, "Effects of processing parameters on tensile properties of selective laser melted 304 stainless steel," Mater. Des., vol. 50, pp. 581-586, 2013.

[21] K. Abd-Elghany and D. L. Bourell, "Property evaluation of 304L stainless steel fabricated by selective laser melting," Rapid Prototyp. J., vol. 18, no. 5, pp. 420-428, 2012.

[22] M. Rombouts, G. Maes, M. Mertens, and W. Hendrix, "Laser metal deposition of Inconel 625: Microstructure and mechanical properties," J. Laser Appl., vol. 24, no. 5, p. 052007, 2012 .

[23] G. P. Dinda, A. K. Dasgupta, and J. Mazumder, "Laser aided direct metal deposition of Inconel 625 superalloy: Microstructural evolution and thermal stability," Mater. Sci. Eng. $A$, vol. 509, no. 1-2, pp. 98-104, 2009.

[24] K. Shah, A. Khan, S. Ali, M. Khan, and A. J. Pinkerton, "Parametric study of development of Inconel-steel functionally graded materials by laser direct metal deposition," Mater. Des., vol. 54, pp. 531-538, 2014.

[25] X. Lin and T. M. Yue, "Phase formation and microstructure evolution in laser rapid forming of graded SS316L/Rene88DT alloy," Mater. Sci. Eng. A, vol. 402, no. 1-2, pp. 294-306, 2005.

[26] X. Lin, T. M. Yue, H. O. Yang, and W. D. Huang, "Laser rapid forming of SS316L/Rene88DT graded material," Mater. Sci. Eng. A, vol. 391, no. 1-2, pp. 325-336, 2005.

[27] P. L. Blackwell, "The mechanical and microstructural characteristics of laser-deposited IN718," J. Mater. Process. Technol., vol. 170, no. 1-2, pp. 240-246, Dec. 2005.

[28] Z. Wang, K. Guan, M. Gao, X. Li, X. Chen, and X. Zeng, "The microstructure and mechanical properties of deposited-IN718 by selective laser melting," J. Alloys Compd., vol. 513, pp. 518-523, Feb. 2012.

[29] S. Kalita, "Direct metal laser deposition of austenitic stainless steel structures: processing and characterization," in Materials Science \& Technology, 2011, pp. 1485-1492. 
[30] M. Ma, Z. Wang, D. Wang, and X. Zeng, "Control of shape and performance for direct laser fabrication of precision large-scale metal parts with 316L Stainless Steel," Opt. Laser Technol., vol. 45, no. 1, pp. 209-216, 2013.

[31] K. Zhang, S. Wang, W. Liu, and X. Shang, "Characterization of stainless steel parts by Laser Metal Deposition Shaping,” Mater. Des., vol. 55, pp. 104-119, 2014.

[32] L. Kaufman and J. Ågren, "CALPHAD, first and second generation - Birth of the materials genome," Scr. Mater., vol. 70, pp. 3-6, Jan. 2014.

[33] L. Kaufman and H. Bernstein, Computer calculation of phase diagrams. Academic Press, 1970.

[34] Z.-K. Liu, "First-Principles Calculations and CALPHAD Modeling of Thermodynamics," J. Phase Equilibria Diffus., vol. 30, no. 5, pp. 517-534, Sep. 2009.

[35] "Thermo-Calc Software and Databases," 2015. .

[36] G. F. van der Voort and H. M. James, "Wrought Stainless Steels," in ASM Handbook vol. 9: Metallography and Microstructures, Materials Park, OH: ASM International, 1985, pp. 279-296.

[37] J. R. Davis, Ed., ASM Specialty Handbook: Stainless Steels. Materials Park, OH: ASM International, 1994.

[38] A. Brooks and A. W. Thompson, "Microstructural development and solidification cracking susceptibility of austenitic stainless steel welds," Int. Mater. Rev., vol. 36, no. 1, pp. 16-44, 1991.

[39] D. B. Williams and C. B. Carter, Transmission Electron Microscopy: A Textbook for Materials Science, 2nd ed. New York: Springer, 2009.

[40] J. W. Elmer, S. M. Allen, and T. W. Eagar, "Microstructural development during solidification of stainless steel alloys," Metall. Trans. A, vol. 20, no. 10, pp. 2117-2131, 1989.

[41] R. Jenkins and R. L. Snyder, Introduction to X-ray Powder Diffractometry. New York: John Wiley \& Sons, Inc., 1996.

[42] L. E. Murr, E. Martinez, S. M. Gaytan, D. A. Ramirez, B. I. MacHado, P. W. Shindo, J. L. Martinez, F. Medina, J. Wooten, D. Ciscel, U. Ackelid, and R. B. Wicker, "Microstructural architecture, microstructures, and mechanical properties for a nickel-base superalloy fabricated by electron beam melting," Metall. Mater. Trans. A Phys. Metall. Mater. Sci., vol. 42, no. 11, pp. 3491-3508, 2011.

[43] I. Shuro, H. H. Kuo, T. Sasaki, K. Hono, Y. Todaka, and M. Umemoto, “G-phase precipitation in austenitic stainless steel deformed by high pressure torsion," Mater. Sci. Eng. A, vol. 552, pp. 194-198, Aug. 2012.

[44] P. E. A. Turchi, L. Kaufman, and Z. K. Liu, "Modeling of Ni-Cr-Mo based alloys: Part II Kinetics," Calphad-Computer Coupling Phase Diagrams Thermochem., vol. 31, no. 2, pp. 237-248, 2007.

[45] A. F. Padilha and P. R. Rios, "Decomposition of Austenite in Austenitic Stainless Steels," 
ISIJ Int., vol. 42, no. 4, pp. 325-327, May 2002.

[46] E. Rudy, C. E. Brukl, and S. Windisch, "Constitution of Niobium (Columbium)Molybdenum-Carbon Alloys," Trans. Metall. Soc. AIME, vol. 239, pp. 1796-1808, 1967.

[47] Z.-K. Liu, "Thermodynamic calculations of carbonitrides in microalloyed steels," Scr. Mater., vol. 50, no. 5, pp. 601-606, Mar. 2004.

[48] B. Weiss and R. Stickler, "Phase instabilities during high temperature exposure of 316 austenitic stainless steel," Metall. Trans., vol. 3, no. 4, pp. 851-866, Apr. 1972.

[49] “AK Steel 304/304L Stainless Steel Product Data Sheet," 2013. [Online]. Available: http://www.aksteel.com/pdf/markets_products/stainless/austenitic/304_3041_data_bulletin .pdf.

[50] “INCONEL ® alloy 625,” Special Metals Corporation, SMC-020, 2006. [Online]. Available: http://www.specialmetals.com/assets/documents/alloys/inconel/inconel-alloy625lcf.pdf.

[51] B. Yao, X.-L. Ma, F. Lin, and W.-J. Ge, "Microstructure and mechanical properties of Ti6Al-4V components fabricated by laser micro cladding deposition," Rare Met., vol. 34, pp. $445-451,2015$.

[52] A. R. Nassar and E. W. Reutzel, "Additive Manufacturing of Ti-6Al-4V Using a Pulsed Laser Beam,” Metall. Mater. Trans. A, vol. 46, no. 6, pp. 2781-2789, 2015.

[53] B. E. Carroll, T. A. Palmer, and A. M. Beese, "Anisotropic tensile behavior of Ti-6Al-4V components fabricated with directed energy deposition additive manufacturing," Acta Mater., vol. 87, pp. 309-320, 2015. 


\section{Figures}
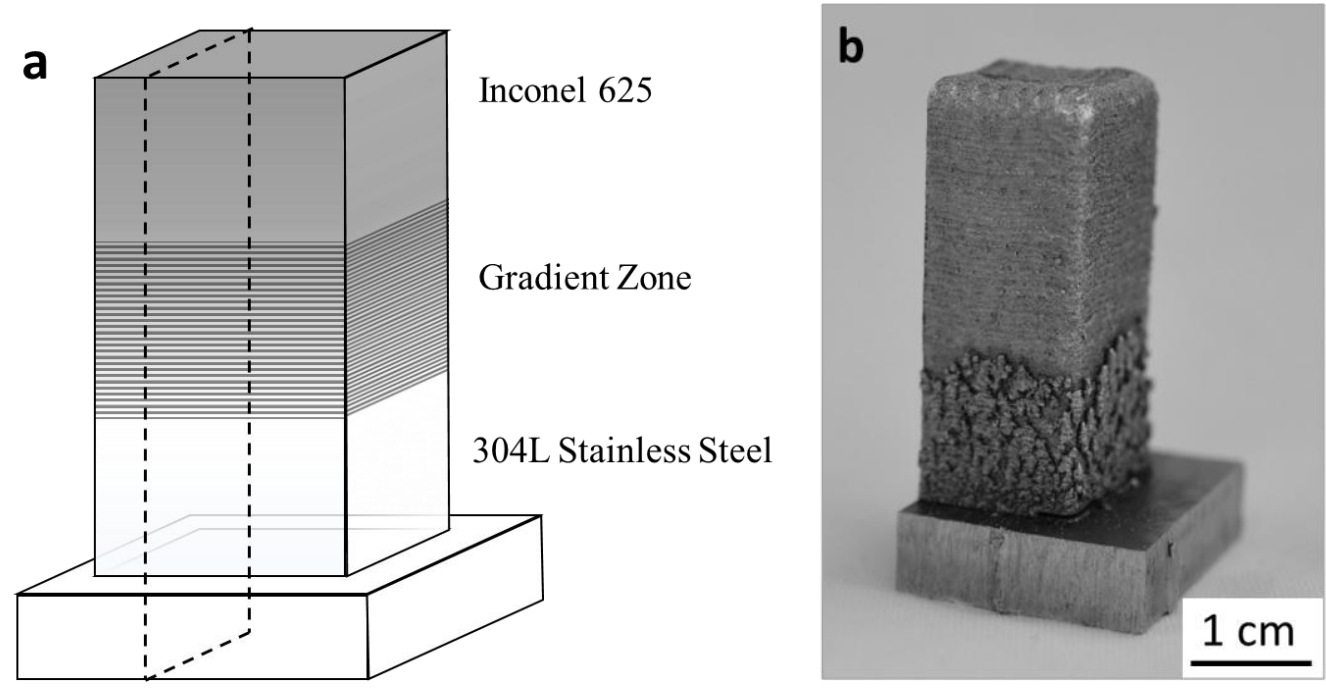

Figure 1. (a) Schematic of gradient alloy specimen. Dotted line shows where part was sectioned for analysis. (b) Photograph of specimen after sectioning. 


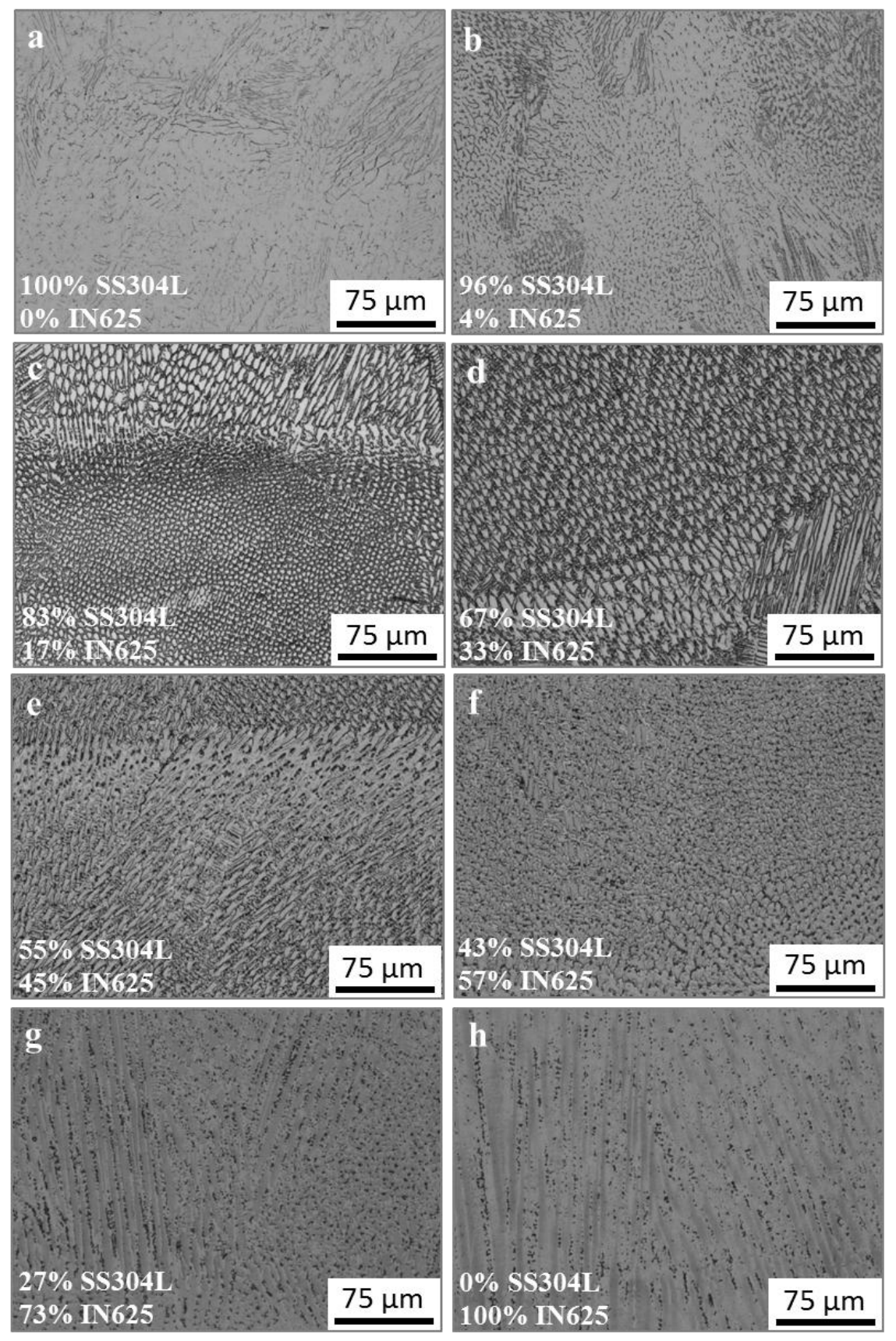

Figure 2. Microstructure of gradient zone from 100\% SS304L (a) to 100\% IN625 (h), with weight fractions of SS304L and IN625 indicated. The gradient microstructure resembles that of austenitic SS304L up to a composition of about $15 \mathrm{wt} \%$ IN625 (a,b,c). A high-contrast cellular dendritic structure appears between $15 \mathrm{wt} \%$ and about $50 \mathrm{wt} \%$ IN625 (c,d,e), and from $50 \mathrm{wt} \%$ to $100 \mathrm{wt} \%$ IN625 $(\mathrm{f}, \mathrm{g}, \mathrm{h})$ the microstructure appears much as IN625, with columnar dendrites. 


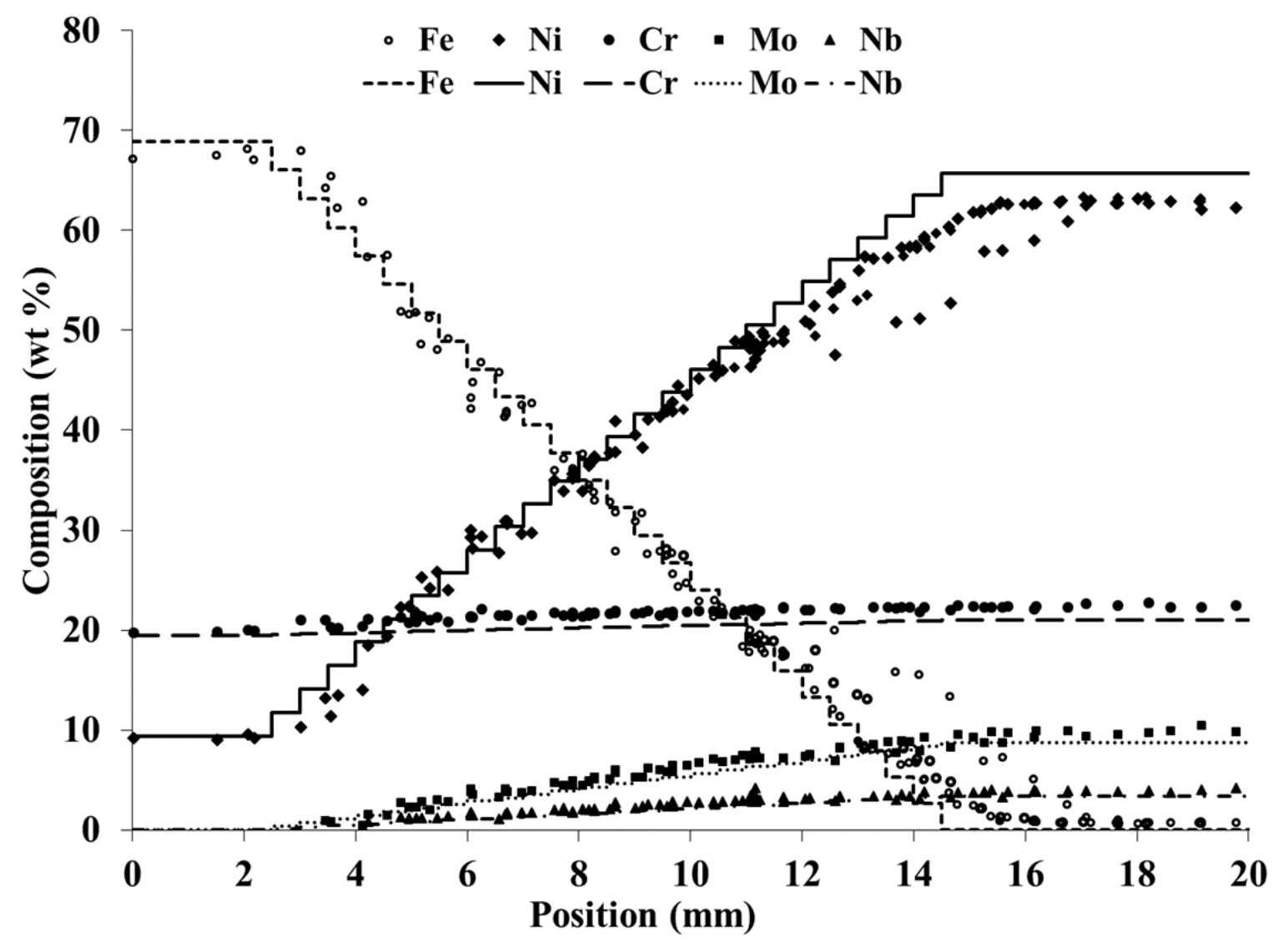

Figure 3. Measured (symbols) and planned (lines) composition of gradient alloy post. The distance from the SS304L baseplate, shown on the x-axis, is nearly linear with the weight fraction of IN625 powder, such that distances less than 2mm correspond to SS304L, while $15 \mathrm{~mm}$ and above correspond approximately to IN625. 


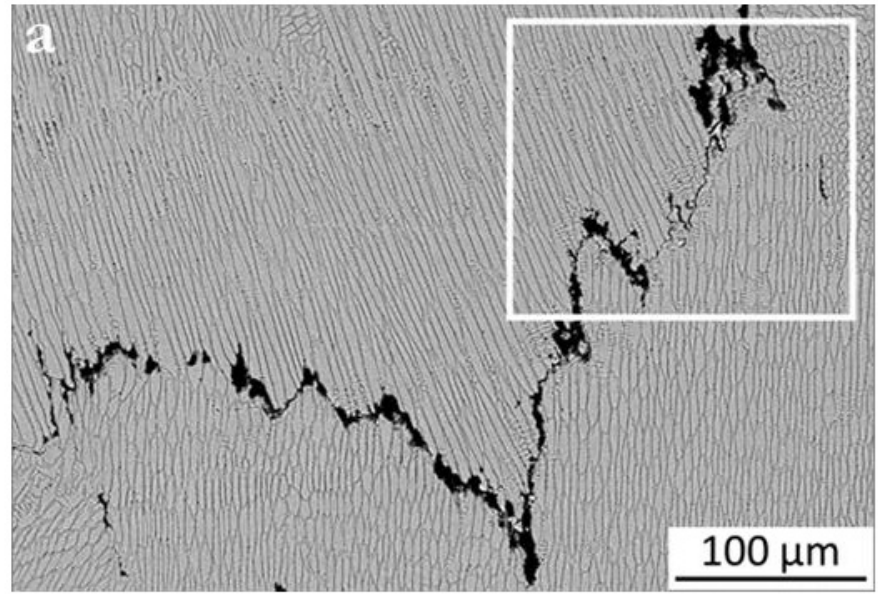

\begin{tabular}{|c|c|c|}
\hline \multicolumn{1}{l|}{ b } & Design & Actual \\
\hline $\mathrm{Fe}$ & 54.6 & 56 \\
\hline $\mathrm{Cr}$ & 19.8 & 20 \\
\hline $\mathrm{Ni}$ & 21.1 & 18 \\
\hline $\mathrm{Mo}$ & 1.8 & 2 \\
\hline $\mathrm{Mn}$ & 1.1 & 1 \\
\hline $\mathrm{Nb}$ & 0.7 & 1 \\
\hline
\end{tabular}
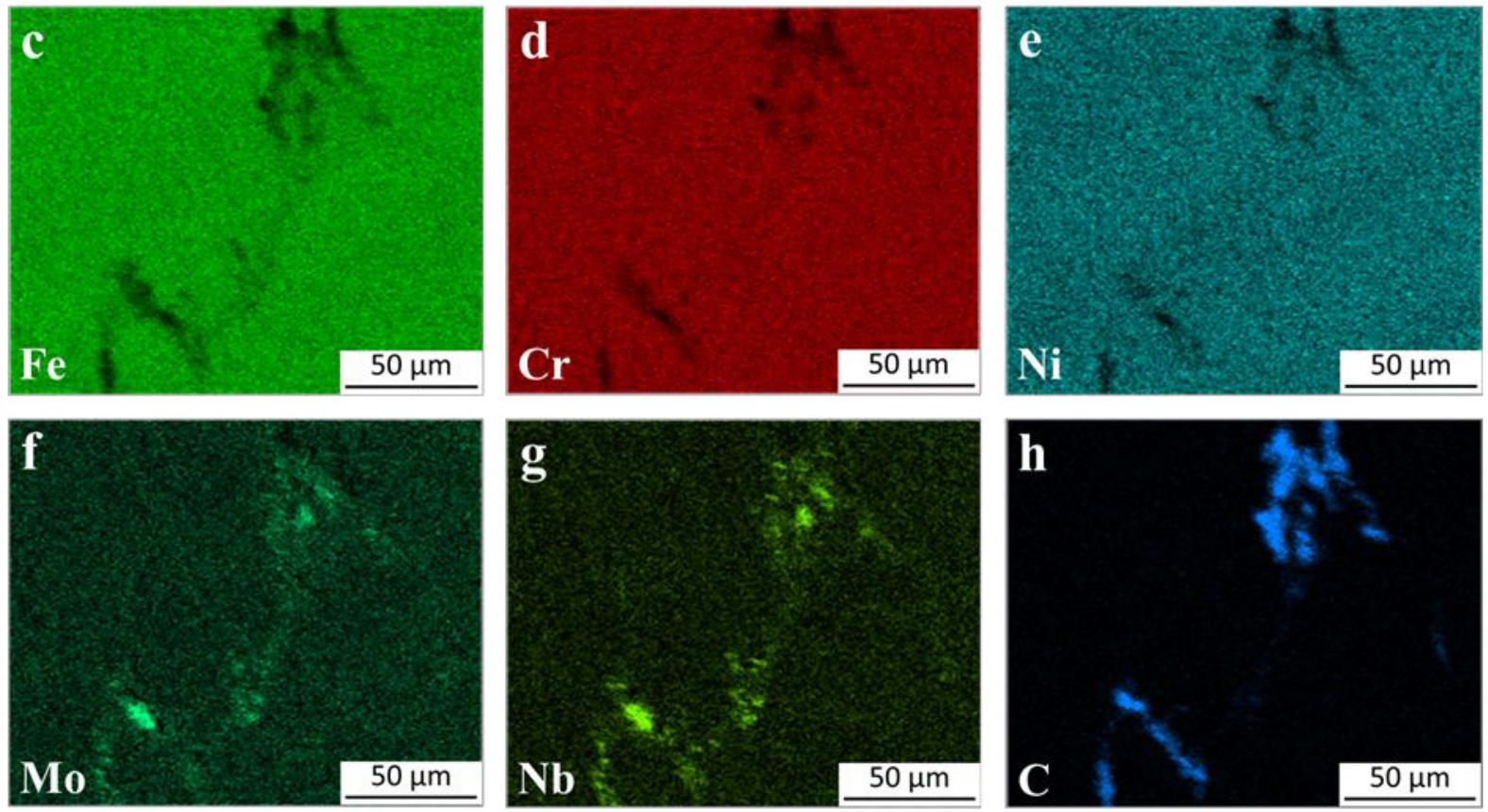

Figure 4. BSE image of crack (a); table of planned and measured composition in weight percent 100 microns from crack (b); EDS maps of constituent elements (c-h). 


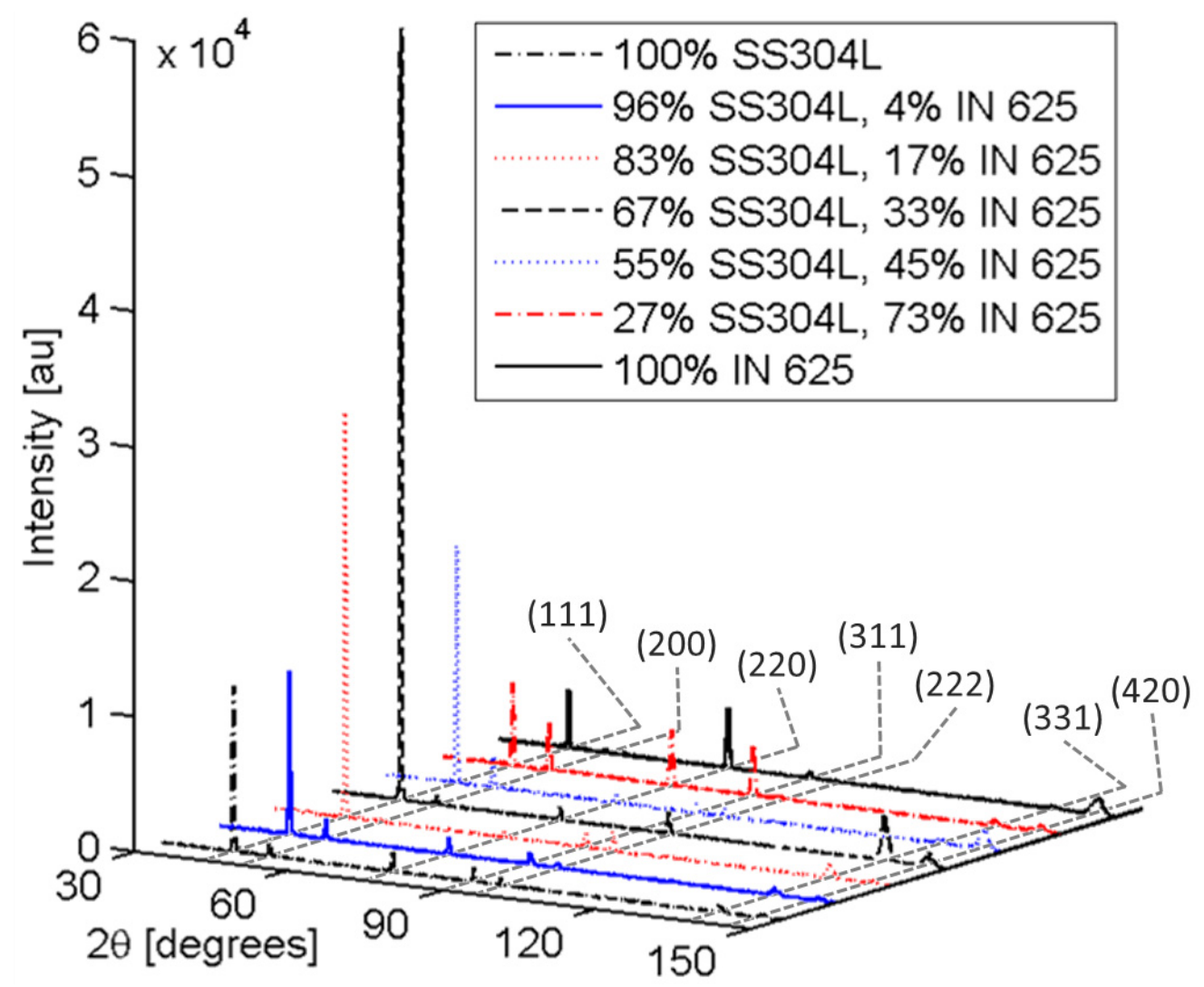

Figure 5. X-ray diffraction patterns along the length of the gradient zone, with weight fractions of two alloys indicated. 


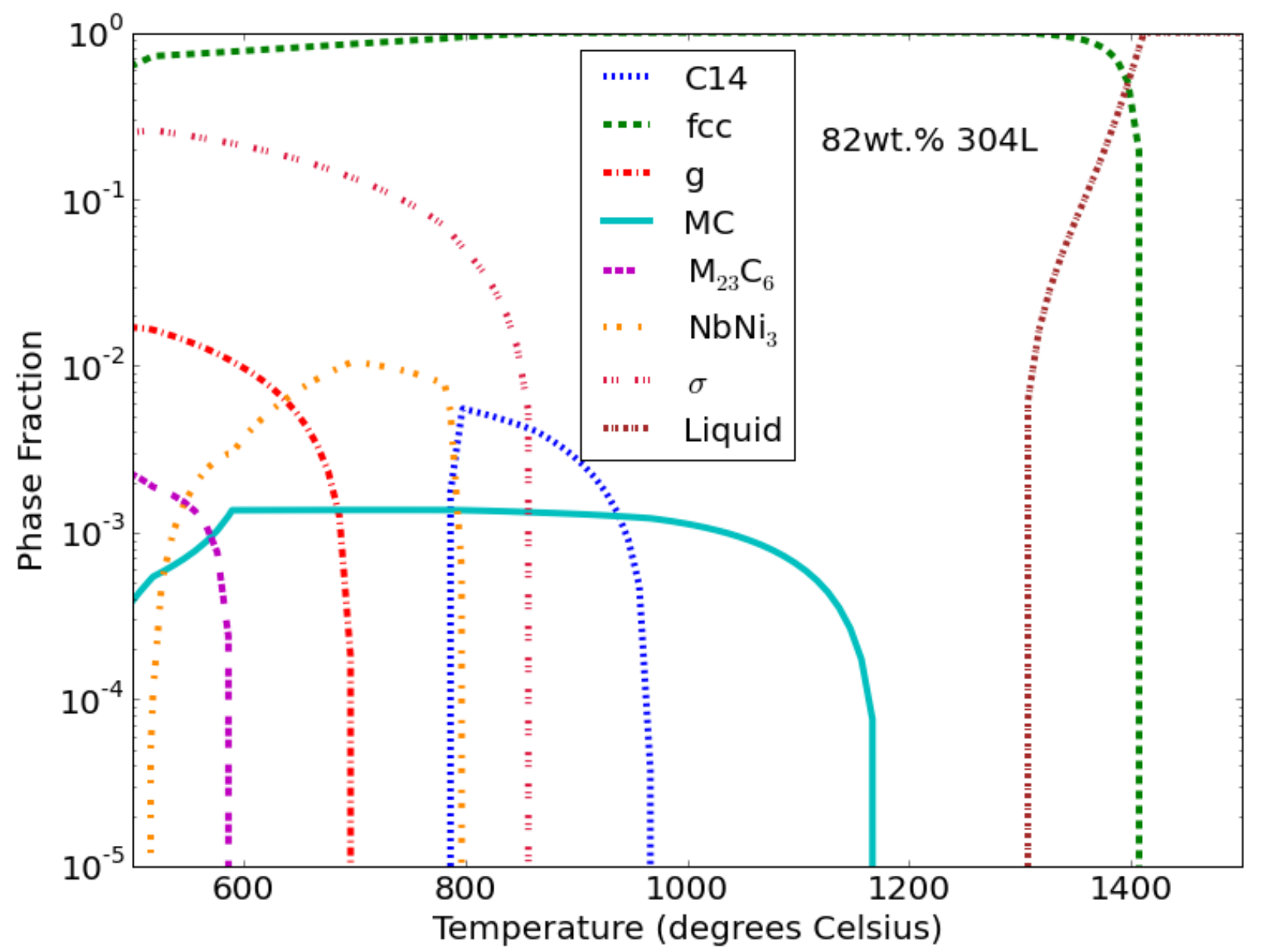

Figure 6. Equilibrium phase fractions as a function of temperature for the measured composition of the SS304L-rich gradient zone boundary are computed using the Thermo-Calc TCFE7 database. This is equivalent to a hypothetical infinitely slow cooling or heating process in which the alloy is allowed to equilibrate at each temperature step. The phase fractions are plotted on a logarithmic scale to make minor phase amounts more apparent. The metal monocarbide (MC) phase is stable from approximately $580^{\circ} \mathrm{C}$ to $1100^{\circ} \mathrm{C}$. 


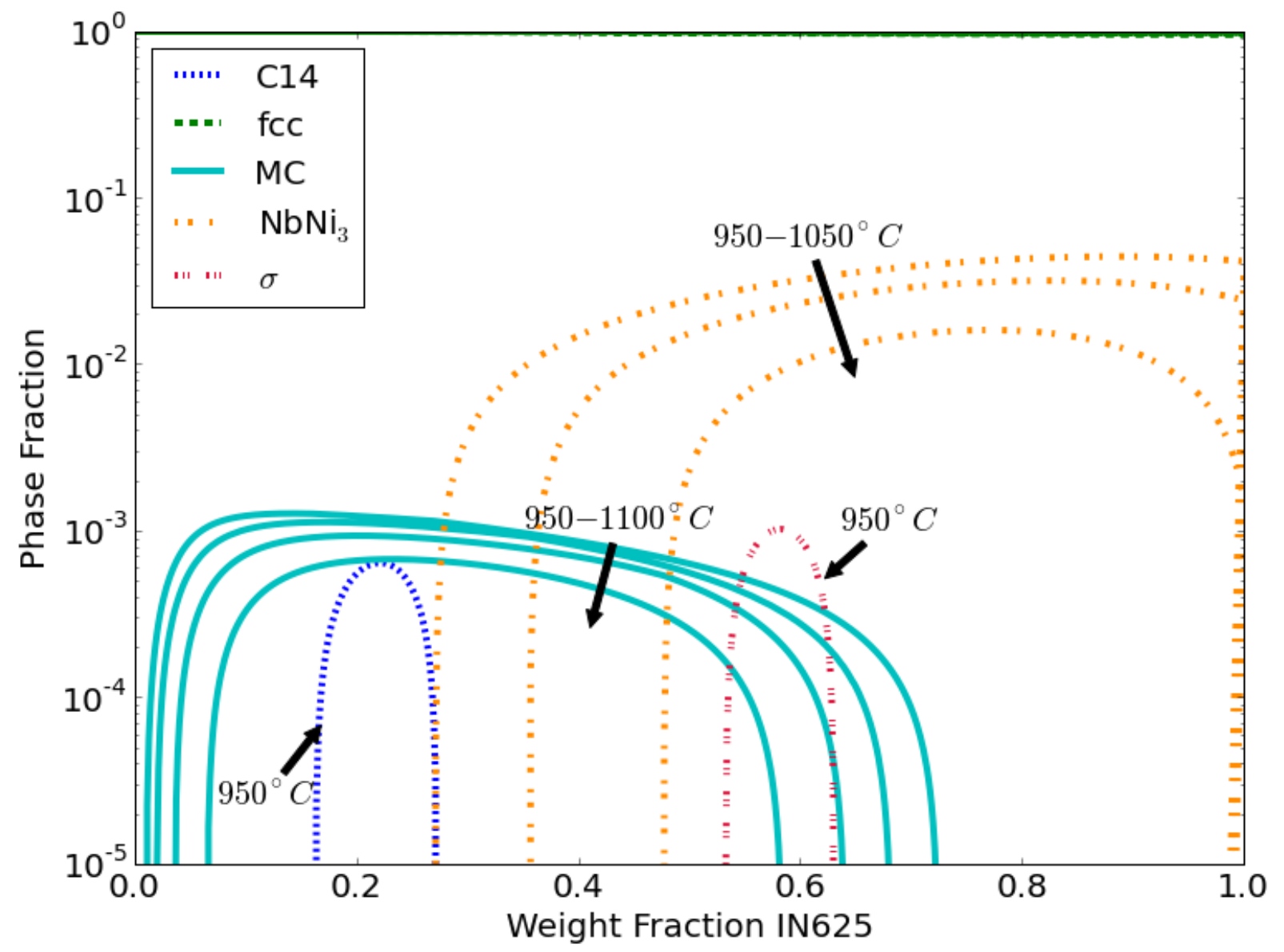

Figure 7. Calculated equilibrium phase fractions as a function of the weight fraction of IN625 powder. A weight fraction of zero corresponds to the SS304L end of the gradient. The phase fractions are computed using the Thermo-Calc TCFE7 database and plotted on a logarithmic scale to make minor phase amounts more apparent. At $1100^{\circ} \mathrm{C}$ the metal monocarbide (MC) phase fraction has a maximum at $23 \mathrm{wt} \%$ IN625. The fcc matrix phase is dominant at all temperatures shown. 


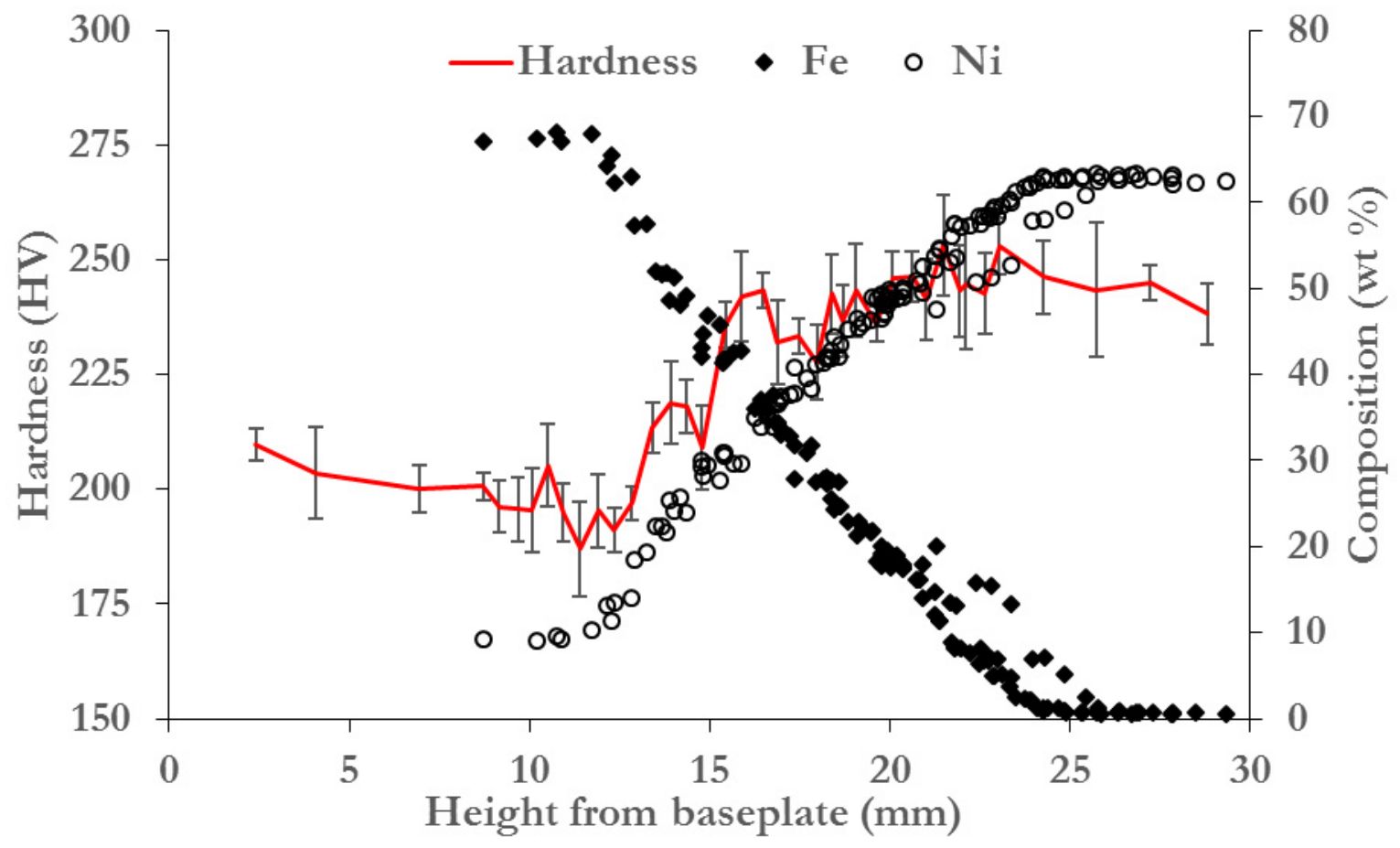

Figure 8. Microhardness of the gradient alloy overlaid on Fe and Ni composition.

Microhardness values are an average of five measurements, with standard deviation indicated by error bars. 


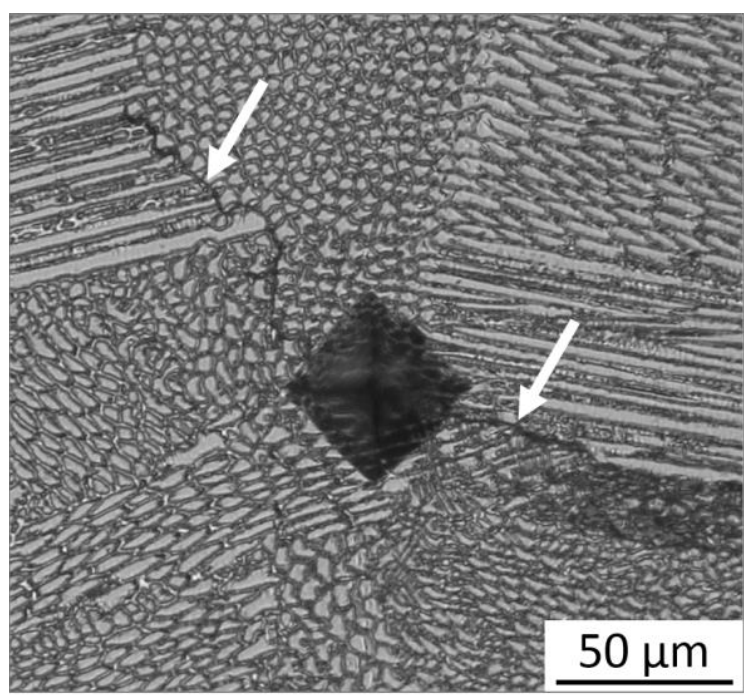

Figure 9. Microhardness indent showing radiating cracks (arrows) arrested after 100 microns or less. 


\begin{tabular}{|c|c|c|}
\hline & Inconel 625 & 304L Stainless \\
\hline $\mathrm{C}$ & $<0.01$ & 0.017 \\
\hline $\mathrm{Mn}$ & 0.36 & 1.31 \\
\hline $\mathrm{Si}$ & 0.36 & 0.66 \\
\hline $\mathrm{Cr}$ & 21 & 19.5 \\
\hline $\mathrm{Mo}$ & 8.7 & - \\
\hline $\mathrm{Co}$ & 0.3 & - \\
\hline $\mathrm{Ti}$ & 0.07 & - \\
\hline $\mathrm{Al}$ & 0.09 & - \\
\hline $\mathrm{Fe}$ & $<0.1$ & 68.9 \\
\hline $\mathrm{Ni}$ & 65.7 & 9.4 \\
\hline $\mathrm{Nb}$ & 3.4 & - \\
\hline
\end{tabular}

Table 1. Composition of powders used in weight percent. 

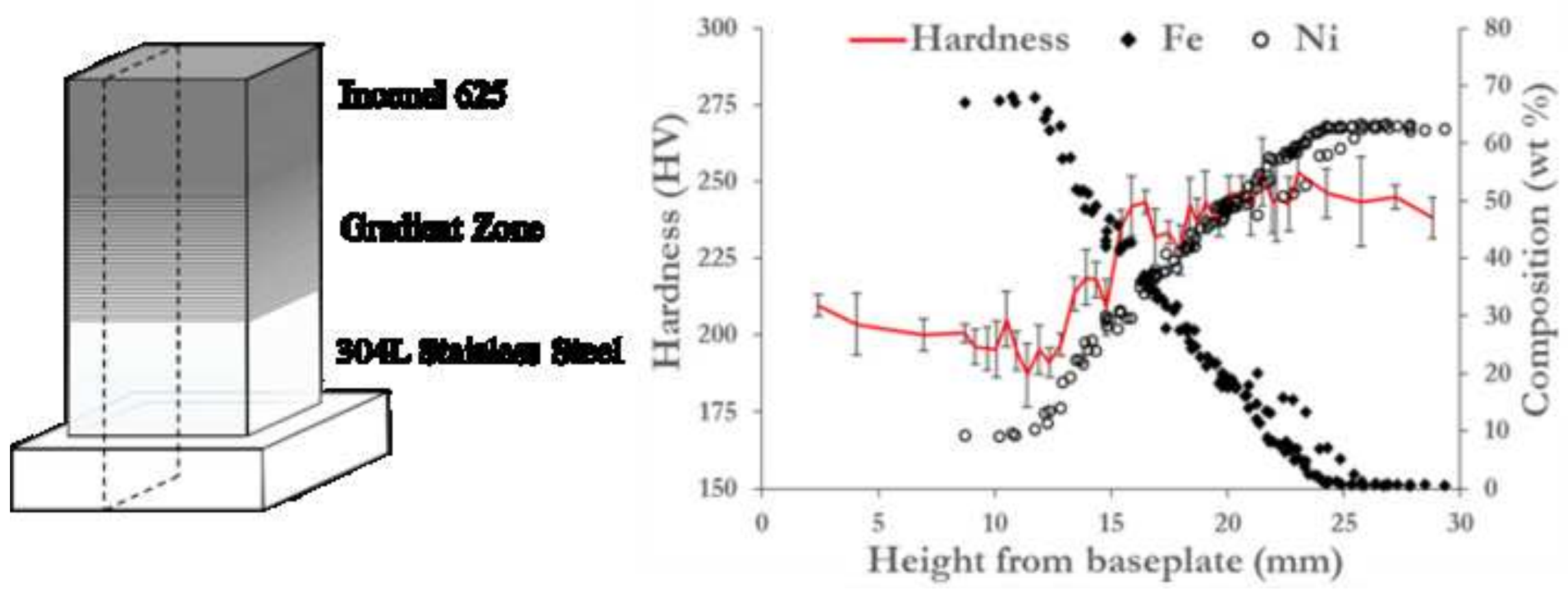